УДК 37.013

\title{
СОЦИОКУЛЬТУРНАЯ СУЩНОСТЬ ПРОЦЕССОВ ИНФОРМАТИЗАЦИИ
}

\author{
(C) 2012 г. Н. С. Борцов
}

\section{Южный федеральный университет, г. Ростов-на-Дону}

С сочиокультурных позищий рассматривается процесс информатизации современного общества, в частности, сочиокультурный статус новых информационных технологий обучения.

Ключевые слова: информация; информационная культура; соииокультурная сущность; новые информационные технологии обучения.

In the article author reviews the process of nowadays society's informatization from the point of social and cultural studies, and defines social ad cultural status of the new information technologies for the education.

Key words: information; informational culture; social and cultural essence; new information technologies for the education.

Главной целью данной статьи является описание сущности новых информационных технологий обучения как социокультурного феномена, инициирующего особые социальные и культурные процессы, происходящие в ходе становления информационного общества и соответствующей ему системы образования.

Во второй половине XX века весьма популярными стали теории информационного общества, которые разрабатывали такие мыслители как Д. Белл, О. Тофлер, Е. Масуда и др. Они утверждали, что возникновение новых информационных технологий приведет к созданию информационного общества, которое переструктурирует экономическую, культурную, интеллектуальную жизнь человечества. Оптимисты говорили, что именно новые информационные технологии дадут возможность разрешить все те противоречия, которые возникли к концу XX века - противоречия экономические, политические, социальные и культурные. С точки зрения данных теоретиков, изменится характер и состав рабочей силы, нивелируются различия между богатыми и бедными в пользу структурирования отношений между людьми в ходе овладения новыми информационными технологиями. Возникнет новая ситуация в политической сфере, поскольку эти технологии дадут возможность каждому человеку участвовать в политической жизни общества, причем прямым и непосредственным образом. Появление и быстрое распространение интернета первоначально укрепило эти иллюзии и казалось, что возникновение нового информационного общества не за горами.

Однако уже в 90-е годы XX столетия обнаружились серьезные трудности, которые стоят перед современным обществом, и эти трудности были связаны в том числе и с распространением интернета, новых информационных технологий. Уже в 1995 году английский социолог Энтони Гидденс говорил о том, что информационное общество есть продукт, скорее, не научного ума, а утопически-гуманистического дискурса. Призрак информационного общества, хотя и бродит по Европе, однако нигде не реализуется в той мере, как это видели теоретики данной концепции. Появился целый ряд проблем, которых раньше не было. Например, заговорили о психологической и социальной зависимости индивида от новых технологий. Одним из первых на это указал английский психолог М. Гриффитс, который специализировался в 
свое время на изучении психологии игроков в азартных играх. Однако еще раньше об этом с тревогой писал такой ведущий фантаст как Клиффорд Саймак. Он писал: «Нет ничего дурного в технике как таковой, дурно лишь наше бездумное увлечение ею. Мы обожествляем машины; в каком-то смысле мы продали им свои души. ... Существуют другие, высшие ценности, помимо тех, что несет с собой технический прогресс. ... Под влиянием техники наше общество и мировосприятие теряют человечность» [1].

Новые информационные технологии обучения, по сути своей, относятся к той группе явлений, которые привлекают внимание специалистов из различных областей знания социологов, философов, культурологов, психологов, педагогов и т. д. Сложность объекта исследования определяется его глубинной полифункциональной значимостью, во многом отражающей духовную и социокультурную ситуацию, возникшую в обществе конца $\mathrm{XX}$ в.

Важное общеметодологическое значение для анализа социокультурной сущности новых информационных технологий обучения имеют работы Н. Бердяева, О. Шпенглера и М. Хайдеггера, исследовавших противоречия между техникой и «нематериальной культурой». В парадигме социально-исторического детерминизма особое внимание уделяется изучению механизма социального воздействия техники на общество.

Значительный интерес для исследования проблемы представляет философия и социология техники, особенно работы 19701980-х гг., в которых были зафиксированы парадигмальные основы данного научного направления (Э. В. Ильенков, С. Карпентер, К. Р. Мегрелидзе, Ю. С. Мелещенко, Л. Мэмфорд, Г. Рополь, Г. М. Тавризян, А. Хунинг и др.). Главное, что и подчеркивают все названные авторы - фиксация сложности исследуемого феномена, его многоаспектности и необходимости междисциплинарного подхода к его изучению. В рамках философии техники наиболее важным для исследования новых информационных технологий является общий подход к технике как к феномену, соединяющему (или разъединяющему) человека и бытие. Идея «духовного овладения» техникой, почти ритуальная для западной общественной мысли, предполагает, по крайней мере, представление об особой «нетехнической» ее сущности.

Антропологическое определение рассматриваемого нами явления состоит в том, что техника - это определенным образом организованная человеческая деятельность, «совокупность действий знающего человека, направленных на господство над природой» [2].

К технике относятся изготовление и применение инструментов, орудий, машин. Это изготовление и применение включают в себя потребности и цели, которым служит техника. Последняя есть как совокупность орудий, так и средство для достижения целей, продуцирующее определенный способ понимания и восприятия действительности. Поэтому решение проблемы новых информационных технологий в значительной степени связано с выявлением их социокультурной значимости, зависимости от ценностных и социальных ориентаций человека и общества.

В педагогических изданиях, начиная со второй половины 80-х гг. прошлого века, наблюдается настоящий бум публикаций, посвященных новым информационным технологиям обучения. Наш анализ показывает, что, несмотря на снижение первоначальной эйфории по поводу появления компьютера в образовательных учреждениях, количество статей по вопросам компьютеризации в педагогических журналах явно больше, чем по другим рубрикам педагогической науки. Данное обстоятельство связано с существованием целого поля проблем, возникающих в ходе информатизации образования.

В связи с этим отечественными и зарубежными учеными в 1980-1990-х гг. активно проводились исследования по проблемам эффективности новых информационных технологий обучения (М. Афанасьев, Д. Дадли, А. Ершов, С. Керр, С. Кокс, С. и Дж. Кулик, В. Лунетта, М. Соболевский, М. Уайд и др.). Большинство специалистов считает, что современное образование находится на пути серьезнейших изменений, связанных с созданием новых систем обучения. Это произойдет в ближайшие десятилетия. Изменятся характер обучения, организация учебной работы и роль преподавателей. Однако все еще остается невыясненным вопрос: какие положительные и какие отрицательные социаль- 
ные и культурные последствия принесут эти изменения? Поэтому одной из главных задач современной социологической науки является теоретическое осмысление процессов информатизации общества.

Важное значение в формировании комплексных исследований процессов информатизации имеет изучение современной «информационной культуры». К данной проблеме, начиная с 1970-1980-х гг, стали проявлять активный интерес социологи, науковеды, специалисты по информатике и семиотике. В рамках этого научного направления ставилась задача исследовать закономерности информатизации современного общества, пути становления информационной культуры.

Особое теоретико-методологическое значение для исследования проблем современной информационной культуры имеют работы американского социолога и антрополога М. Мид, посвященные изучению способов трансляции социального опыта между поколениями. Она выделяет понятие префигуративной культуры, в которой взрослые учатся даже у своих детей. Именно такого рода культура, формирующаяся во многом под воздействием новых информационных технологий, возникает в конце XX - начале XXI в.

Несмотря на ряд серьезных теоретических достижений в области исследования эффективности новых информационных технологий обучения, влияния процесса информатизации образования на общество, чувствуется настоятельная необходимость выхода за рамки узкоспециализированных педагогических или психологических подходов.

Один из крупнейших и оригинально мыслящих философов России В. В. Розанов еще в 1899 г. писал: «Мы не имеем и не имели того, что можно назвать философией воспитания и образования, т. е. обсуждение самого образования, самого воспитания в ряду остальных культурных факторов и также в отношении к вечным чертам человеческой природы и постоянным задачам истории» [3]. Эта мысль остается во многом актуальной и сейчас.

В данном контексте понятен тот всплеск интереса, который проявляют теоретики и практики, широкая научная общественность к комплексу проблем, изучаемых в рамках философии образования и социологии об- разования. Рассмотрение образовательного процесса с философско-методологической, социологической, культурологической позиций становится «категорическим императивом», без следования которому невозможно решать современные педагогические и дидактические проблемы.

Речь идет об осмыслении социокультурных процессов в системе образования, связи образовательной сферы с жизнью человека и общества, социальной обусловленности взаимодействия учащегося и учителя в процессе обучения. Эти вопросы имеют особое значение в периоды кризисного развития общества. Требуется глубокая социологическая разработка проблем специфики образования в кризисные периоды, новых функций преподавателей (В. Т. Лисовский).

Новые информационные технологии обучения в данном контексте выступают в качестве важнейшего элемента возникновения «компьютерной революции» (Беркли, Хокс, Ракитов), «технотронной эры» (Бжезинский), «века информации» (Хелви), «информационной революции» (Ламбертон), «телематического общества» (Мартин), «информационного общества» (Масуда, Тоффлер, Кислер, Дилигенский), «информационно-экологической цивилизации» (Урсул).

Тем не менее, существует большой разброс во мнениях, позициях и результатах исследований по проблемам эффективности новых информационных технологий обучения. Данное обстоятельство, на наш взгляд, обусловлено прежде всего тем, что отсутствует целостное представление о социокультурной сущности рассматриваемого феномена. Если предметом анализа окажется не социокультурная, а техническая природа новых информационных технологий обучения, то сущность современного образовательного процесса познать будет невозможно.

Следует подчеркнуть философско-гуманитарную сущность теории, изучающей новые информационные технологии. Исходным принципом при этом является идея неограниченных потенциальных интеллектуальных возможностей человека, в отличие от компьютера, обладающего ограниченными техническими характеристиками, сколь бы мощным он ни был. Проблема заключается в том, чтобы человек наиболее полно использо- 
вал возможности компьютера, усиливая тем самым свою интеллектуальную мощь. В этом случае можно рассчитывать на социокультурную эффективность применения новых информационных технологий в обучении.

Таким образом, анализ существующей литературы показывает, что возникает настоятельная необходимость внедрять новые информационные технологии обучения, взаимодействие человека и компьютера в образовании концептуально исследовать с социокультурных позиций, как важнейший элемент социокультурной системы общества.

Подчеркнем, что социокультурное явление возникает в ходе взаимодействия людей. Социокультурный порядок неразделим, и нельзя создавать науку на основе одного из аспектов - скажем, социального, игнорируя культурный и личностный аспекты. Социология здесь выступает как генерализующая наука, рассматривающая социокультурную систему как целое - в единстве этих трех аспектов.

Необходимость социокультурного анализа связана и с тем, что трансформируется предмет современной социологии. Культура в современном обществе - это уже не просто пассивное отражение существующих процессов, а их активная формообразующая сторона. Там, где раньше было «общество», возникла «культура» (Бекинг). Особо отметим, что наиболее интересные социологические концепции, возникшие в настоящее время (П. Бурдье, Ю. Хабермаса, М. Элиаса), могут быть в значительной степени отнесены к области социологии культуры. В современной отечественной социологии различным аспектам развития общества и культуры посвящены концептуальные работы 3. Т. Голенковой, М. К. Горшкова, А. В. Дмитриева, В. И. Добренькова, В. Ф. Левичевой, В. Т. Пуляева, Н. С. Слепцова.

Информатика как фундаментальная наука и связанный с ней комплекс научных исследований активно развивается в последнее время. Несмотря на то, что изучение информации началось еще в прошлом веке по многим традиционным научным направлениям, таким как физика, биология, социология, психология и т. д., однако общефилософские проблемы информатики до сих пор еще остаются до конца неисследованными, мно- гие вопросы неизученными. По-видимому, социологам и философам образования необходимо обратить особое внимание на фундаментальные проблемы, связанные с информационными и сетевыми технологиями, сущностью философии информатики. Отметим, что современная наука становится все более информационно-ориентированной, а информатика, следовательно, является не только одной из быстроразвивающихся и наиболее перспективных областей современной науки, но и оказывается основой для фундаментального понимания развития общества, природы и человека. Эта проблема для системы образования является весьма существенной, поскольку на современном этапе развития мировой образовательной системы проблемы качества выдвигаются на первое место.

Собственно философия информации развивалась в России уже более 40 лет. Ее основы заложил академик А. Д. Урсул. Целый ряд его работ, монографий до сих пор являются актуальными и считаются классическими. Следует отметить, что передовые научные дисциплины, лидирующие в XXI веке, такие, например, как генетика, биология нуждаются в понимании роли информации в эволюционном процессе. Для социологов информация является важнейшим моментом в развитии общества, социума. С философской точки зрения можно говорить об общих законах и закономерностях, которые действуют в информационной среде как общества, культуры, так и природы. В связи с этим возрастает роль изучения научных методов информатики. Речь идет об информационном подходе, о методах имитационного моделирования и о методах глубокой виртуальной реальности. Как считает К. Колин, эти методы будут выдвигаться в ближайшие годы на первый план в методологии научных исследований естественнонаучного и гуманитарного направлений мировой науки. Отсюда возникает необходимость пересмотра существующего положения информатики в системе науки и образования и определения ее в качестве самостоятельной научной отрасли, которая имеет серьезное значение для естественных и гуманитарных наук. «Все это должно дать человеку новые возможности для более эффективной организации информационных процессов не только в технических, но и в со- 
циальных системах. Опираясь на эти знания, человек сможет глубже изучить процессы жизнедеятельности биологических систем, а также, возможно, и принципы деятельности своего сознания» [4].

Эти положения дают нам возможность по-новому взглянуть на закономерности окружающего нас мира, исследовать, в том числе, и специфику информационного взаимодействия в социальном мире. Данная ситуация связана также и с тем, что информация пронизывает все уровни организации материи. В широком понимании этого понятия она представляет собой объективное свойство реальности, которое проявляется в асимметрии существования материи и энергии в пространстве и во времени. Материальные и энергетические процессы осуществляются неравномерным образом. В результате все происходящее в обществе, в сознании, в социальном мире, в природе в целом отражается в понятии информации и в закономерностях ее развития. Конечно же, нужно учитывать то, что информация проявляет себя на различных уровнях материи специфическим образом.

Современная система образования ориентируется на новые социокультурные цели, нормы действия и мышления, связанные с динамикой, непрерывным обновлением и изменением современного общества. Новые информационные технологии обучения один из важнейших элементов реформирования традиционной системы образования.

Информатизация образования как социокультурный феномен осуществляется в рамках целостного процесса становления информационного общества. В свою очередь, система образования оказывает мощное воздействие на социальную жизнь, обостряя или разрешая конфликты, противоречия настоящего и будущего.

Современная информационная культура общества дает человеку возможность оставаться в рамках гуманистической парадигмы, поскольку позволяет моделировать и учитывать последствия своих действий. Поэтому образование - не просто питательная среда для научно-технического прогресса, оно также закладывает основы информационной культуры.

Информационную культуру постинду- стриального общества можно сформировать тогда, когда индивид, использующий компьютер, становится субъектом культуры, ее главным действующим лицом. Современная информационная культура - это качественно новый уровень социализации человека через овладение новыми информационными технологиями, позволяющими системным образом видеть, осмыслять и преобразовывать мир и последовательно «выстроить» личностно ориентированный образ культуры как целостности.

Социокультурная сущность новых информационных технологий обучения определяется их местом и ролью в социокультурной структуре общества и возможностями качественно нового способа осмысления действительности, обусловленными самой технологией.

Социокультурная значимость новых информационных технологий обучения заключается в том, что они меняют стиль мышления, образ жизни, способы ориентации человека в социальном пространстве. Являясь необходимым продуктом развития общества второй половины XX в., ответом на вызов современного этапа НТР, новые информационные технологии стали реальной основой для изменения характера развития общественного организма.

Социокультурная значимость новых информационных технологий определяется также тем, что они становятся одновременно средством как профессионализации, так и социализации индивида, как средством получения необходимых производственных и научных знаний для жизни и работы в информационном обществе, так и основой для изменения стиля мышления и ценностных ориентаций подрастающего поколения. Это имеет принципиальное значение, игнорируя которое невозможно определить социальную, культурную, педагогическую значимость внедрения новых информационных технологий обучения.

Новые информационные технологии в зависимости от их социокультурной ориентированности могут послужить основой как для создания штампованного единообразного сознания, подавления творческого начала в личности, «наркотизации духа», тоталитаризации общества, так и для формирования но- 
вой культуры мышления и действия, способа осмысления мира, системы ценностных ориентаций, характерных для информационной цивилизации.

Системный взгляд на мир, алгоритмизация познавательного процесса, ориентация на рефлексивное знание, качественное увеличение «степени свободы» в общении и методах получения нового знания - эти и другие феномены свидетельствуют о глубоких сдвигах не только в современной системе образования, но и в способах и формах социокультурной деятельности человека.

Современная система образования ориентируется на новые социокультурные цели, нормы действия и мышления, связанные с динамикой, непрерывным обновлением и изменением общества начала XXI века. Новые информационные технологии обучения один из важнейших элементов реформирования традиционной системы образования.

Информатизация образования как социокультурный феномен осуществляется в рамках целостного процесса становления информационного общества. В свою очередь, система образования оказывает мощное воздействие на социальную жизнь, обостряя или разрешая конфликты, противоречия настоящего и будущего.

Современная информационная культура общества дает человеку возможность оставаться в рамках гуманистической парадигмы, поскольку позволяет моделировать и учиты- вать последствия своих действий. Поэтому образование - не просто питательная среда для научно-технического прогресса, оно также закладывает основы информационной культуры.

Информационную культуру постиндустриального общества можно сформировать тогда, когда индивид, использующий компьютер, становится субъектом культуры, ее главным действующим лицом. Современная информационная культура - это качественно новый уровень социализации человека через овладение новыми информационными технологиями, позволяющими системным образом видеть, осмыслять и преобразовывать мир и последовательно «выстроить» личностно ориентированный образ культуры как целостности.

\section{Литература}

1. Саймак К. Д. Империя; Город. // Саймак К. Д. Романы. - Рига: Полярис, 1994.

2. Ясперс K. Современная техника. // Новая технократическая волна на Западе. - M., 1986. - C. 120. C. 601.

3. Сумерки просвещения. - М., 1990. -

4. Колин K. К. Философия информации и фундаментальные проблемы современной информатики. // Alma Mater. Вестник высшей школы. - 2010. - №1. - С. 35. 


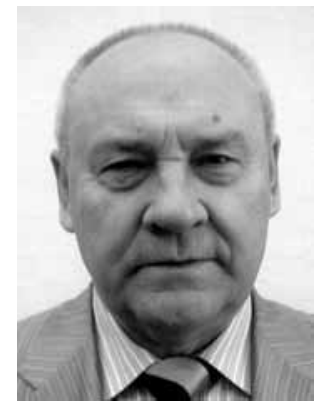

Юрий Сергеевич Борцов - доктор социологических наук, профессор, профессор кафедры социологии, политологии и обществоведческого образования педагогического института Южного федерального университета.

Yuriy Sergeyevich Bortsov - Ph.D., Doctor of Sociology, professor, professor at The Southern Federal University's Institute of Educational Work department of Sociology, Political Science and Social Sciences' Tecahing.

344082, г. Ростов-на-Дону, ул. Б. Садовая, 33

33 Bolshaya Sadovaya st., 344082, Rostov-na-Donu, Russia

Тел.: +7 (863) 272-67-50; e-mail: chair_soc@pi.sfedu.ru

\section{Международный университет Японии (МУЯ) ежегодно присуждает некоторое количество стипендий новым студентам.}

В Университете имеются Школы 1) международных отношений и 2) международного менеджмента, в которых можно получить степени магистра. В числе направлений: государственное управление и политический анализ, международные отношения, международное развитие, управление бизнесом (MBA), управление электронным бизнесом. Обучение ведется на английском языке, но предоставляется возможность изучения и японского.

Иностранным студентам стипендии присуждаются на год, с возможностью продления еще на год.

\section{Стипендии могут быть четырех типов:}

Стипендии памяти Накаяма А-типа:

1) частичное освобождение от платы за зачисление (из 300 тысяч иен платятся 50 тыс.),

2) освобождение от платы за учебу - 1900 тыс. иен (или 2200 тыс. иен),

3) ежемесячные выплаты - 100 тыс., включая плату за общежитие (39 тыс. иен в месяц).

Стипендии памяти Накаяма В-типа:

1) частичное освобождение от платы за зачисление (из 300 тыс. иен платятся 50 тыс.),

2) освобождение от платы за учебу - 1900 тыс. иен (или 2200 тыс. иен).

\section{Стипендии памяти Накаяма C-типа:} иен).

Частичное освобождение от платы за учебу (уменьшение до 570 тыс. иен, или до 660 тыс.

Стипендии памяти Накаяма S-типа

Уменьшение платы за учебу наполовину (до 950 тысяч иен).

Формы заявлений имеются в Межгосударственной ассоциации последипломного образования:

$$
\text { +7 (495) 434-24-38. }
$$

